\title{
LA TEORÍA SOCIAL DE JEAN-JACQUES ROUSSEAU
}

\author{
THE SOCIAL THEORY OF \\ JEAN-JACQUES ROUSSEAU
}

\author{
AINA D. LÓPEZ YÁÑEZ \\ CEAQ. Sorbonne-París V
}

\begin{abstract}
PALABRAS CLAVE ADICIONALES
ADDITIONAL KEYWORDS

Perspectiva sociológica, Teoría general, Sociological Perspective, General Theory, Sociabilidad, Acción social, Alienación. Sociability, Social Action, Alienation.
\end{abstract}

RESUMEN. La interpretación de la obra de Rousseau desde las categorías propias de la teoría sociológica da lugar a una reconstrucción de las propuestas del autor basada en aquellos conceptos fundamentales de la disciplina que serían asentados después por los sociólogos clásicos del siglo XIX. Obviamente, estos conceptos no se encuentran en los escritos de Rousseau en los términos de una teoría formalizada, pero sí como nociones o ideas de gran valor intelectual. En el presente trabajo procedemos a mostrar las grandes líneas de la teoría social de Rousseau. Se expone de este modo nuestra reconstrucción de la visión rousseauniana de la historia humana, de la condición del hombre, de la acción social y de la sociedad como totalidad, teorías que conforman una ontología claramente atravesada por la creencia en la alienación y negatividad consustanciales a los fenómenos sociales.

ABSTRACT. The interpretation of Rousseau's writings from categorical fields of sociological theory make way for a reconstruction of the author's proposals based on fundamental sociological concepts that would later be laid out by classic $19^{\text {th }}$ century sociologists. Obviously, these concepts are not found in Rousseau's work in terms of a formal theory as so much as notions or ideas of great intellectual value. In this paper we proceed to draw out the social theory lines from Rousseau's work. Hence we put forth our reconstruction of a rousseaunian vision of human history, mankind's condition, social action and society as a whole. Theories that make up a social ontology that is clearly marked by the belief of substantiated alienation and negativity both intrinsic to social phenomena.

* Quiero expresar mi gratitud a la Fundación Caja Madrid por la financiación de mi investigación durante el curso 2004-2005 en la Universidad René Descartes, e igualmente a Emilio Lamo de Espinosa por la dirección de mi tesis doctoral.

E-mail: lopezaina@yahoo.fr

Revista Internacional de Sociología (RIS)

Tercera Época, $N^{\circ} 42$, Septiembre-Diciembre, 2005, pp. 181-199 
RIS

REVISTA INTERNACIONAL DE SOCIOLOCÍA

№ 42, SEPTIEMBRE-DICIEMBRE, 2005

AINA D. LÓPEZ YÁÑEZ

\section{INTRODUCCIÓN}

Uno de los calurosos días del verano de 1749 , mientras abordaba el trayecto desde París a Vincennes, Jean-Jacques Rousseau fue presa de una violenta intuición. Súbitamente se le revelaron las contradicciones y abusos del sistema social, la perniciosa acción de las instituciones sobre la bondad natural del hombre y el ímpetu de las pasiones colectivas en la depravación del género humano (Rousseau, 1994:32-33). Según el mismo autor afirmó mucho más tarde, este repentino descubrimiento de la sociedad le perdería para el resto de sus días. Y no era para menos, pues además de permitirle desenmascarar la sociedad humana le proporcionó la sustancia de su crítica a la modernidad, legado por el que ocuparía un lugar de honor entre muchas de las más notables disciplinas entregadas al estudio del hombre.

Sin embargo, pese a su madurez y trascendencia, la dolorida mirada rousseauniana al hombre socializado ha sido esquivada por la Sociología, siempre presta a idealizar el valor social del hombre. No debe olvidarse que en el camino de su institucionalización, sobre todo durante el siglo XIX, nuestra disciplina se entregó frecuentemente a la celebración de la sociabilidad innata, labor de la que ni siquiera se abstuvieron las corrientes críticas, empeñadas más bien en una visión complaciente de la sociedad natural desde la que elevar su juicio a las sociedades en curso. Se explica así lo exiguo de la atención dispensada por los sociólogos a la obra de Rousseau y que a la sazón ésta fuera dirigida hacia un concepto colectivista y triunfante como el de voluntad general (Durkheim, 1966), a fin de cuentas, una noción netamente política.

¿Acaso la teoría social de Rousseau no merece tener un papel más relevante en el futuro de la sociología? Realmente consigue llenar uno de los vacíos característicos de la disciplina: el de una comprensión de lo vacilante, desconsolador y traumático de la vida colectiva en cualquiera de sus manifestaciones. No hay duda de que Rousseau elaboró una solución teórica soberbia en este sentido cuando con total convicción trató de asegurar la bondad del hombre y corregir el error hobbesiano de localizar los fundamentos de la guerra y la maldad en la naturaleza del hombre. Los principios del mal residen en la sociedad: he aquí el legado rousseauniano. El análisis de la sociabilidad como potencialidad extraña a la naturaleza humana, la identificación del juego social como fuente de infelicidad y envilecimiento o la representación de la sociedad como pura opacidad bien merecen una reflexión serena, una reflexión que logre arrancarnos del sueño decimonónico y nos prepare para un futuro que amenaza con no plegarse a los límites de la sociología clásica. Con ese propósito comenzamos nuestra revisión teórica de la idea de sociedad esbozada por Rousseau.

\section{DE LA ASOCIABILIDAD HUMANA A LA PRIMACÍA DE LO SOCIAL}

Antes que nada debe afirmarse que en la progresión intelectual rousseauniana se advierte la clara articulación de una perspectiva analítica sociológica al modo 
cómo sería formalizada con posterioridad por la tradición realista francesa: "es en la naturaleza de la sociedad misma donde hay que ir a buscar la explicación de la vida social" (Durkheim, 1978:127)1. Esta circunstancia anima por sí misma a determinar la verdadera entidad de la aportación de Rousseau a la sociología ${ }^{2}$, al tiempo que invita a una revisión de su influencia en los orígenes de nuestra disciplina, ampliando los argumentos con que acreditar una exégesis sociológica de su obra.

Podría ocurrir, sin embargo, que el conocedor de la demarcación disciplinar durkheimiana experimentara cierta confusión ante una lectura de la obra de Rousseau que insiste en su carácter sociológico. La proyección de la perspectiva sociológica resultó sencilla a Durkheim gracias a la defensa de la superioridad ontológica y moral de lo social sobre el sujeto contenida en su teoría de la sociedad, elemento que el francés trabó con una concepción social o sociable de la naturaleza humana que no podemos hallar en la antropología rousseauniana fundamental ${ }^{3}$ : la asociabilidad, y no la sociabilidad, era el rasgo consustancial al hombre según los presupuestos antropológicos rousseaunianos. No obstante, es seguro también que el autor consideraba nuestro destino fatalmente abocado a una especie de socialización universal cuya posibilidad residía paradójicamente en el normal perfeccionamiento de algunas de las habilidades inherentes a la humanidad. Gracias a esta hipótesis de un proceso de socialización del género humano, Rousseau emprendió una reflexión que abriría su discurso antropológico a una nueva dimensión: la del hombre social real. Paralela a la disertación antropológica tomaría cuerpo así

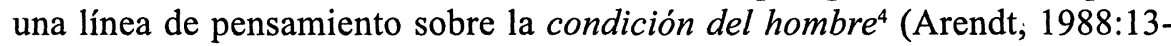
19), decidiendo un desarrollo bifronte de su obra visible en la antítesis entre el estado de naturaleza y el estado de sociedad, en la radical segregación entre nuestra naturaleza y nuestra condición.

\footnotetext{
${ }^{1}$ El autor venía a definir la perspectiva sociológica como aquella trama explicativa en que se investiga lo social articulando variables sociales, y no atendiendo al ascendente de órdenes distintos al conformado por los fenómenos colectivos.

${ }^{2}$ De lo que se trata aquí, entonces, es de salvar el evidente anacronismo y reconstruir en los términos de un sistema verdaderamente sociológico una filosofia de la sociedad que precedió a la constitución de la Sociología como ciencia.

${ }^{3}$ No obstante, si fuera el objeto del presente artículo, mostrariamos que las diferencias entre las concepciones rousseaunianas y durkheiminas del sujeto son mucho menos significativas de lo que podría parecer a primera vista, pues Rousseau desarrolló una reflexión sobre el hombre social que guarda algunas similitudes con el bosquejo de la sociabilidad humana acometido por Durkheim. En este sentido, pueden revisarse los comentarios del propio Durkheim (Lukes, 1984:635).

${ }^{4}$ Es necesario considerar aquí la diferenciación entre la "naturaleza" y la "condición" del hombre establecida por Hannah Arendt.
} 
RIS

REVISTA INTERNaCIONAL DE SOCIOLOGÍA

№ 42, SEPTIEMBRE-DICIEMBRE, 2005

AINA D. LÓPEZ YÁÑEZ

"Los hombres son malvados; una triste y continua experiencia nos dispensa de probarlo; sin embargo, el hombre es naturalmente bueno, creo haberlo demostrado [...]. Que admiren cuanto quieran la sociedad humana, no será por ello menos cierto que necesariamente conduce a los hombres a odiarse entre sí en la medida en que sus intereses se cruzan, a prestarse mutuamente servicios aparentes y a hacerse en la práctica todos los males imaginables [...]”. (Rousseau, 1982:309).

Ahora bien, la bifurcación de la obra rousseauniana concierne aquí especialmente porque consumó la articulación de una perspectiva de análisis que puede designarse sociológica en el sentido apuntado anteriormente. Contra lo que pudiera parecer a primera vista, el asociologicismo abrazado por Rousseau en su antropología fundamental no bloqueó el desarrollo de un discurso sociológico, más bien lo favoreció, pues las acciones de los hombres reales en el mundo real en modo alguno se plantearon como indicadores antropológicos, sino más bien como fenómenos inducidos por la socialización del género humano, esto es, como indicadores puramente sociológicos. El principio, el desenlace y el recorrido de los acontecimientos relatados en la crónica rousseauniana remiten siempre a la dinámica específica de lo social, a los efectos de la socialización de la humanidad.

\section{LA HISTORIA, COMO CRÓNICA DE LA SOCIALIZACIÓN DE LA HUMANIDAD}

Claro que Rousseau debió resolver la paradoja contenida en su propuesta. De un lado proclamaba nuestra consustancial asociabilidad; de otro lado señalaba el advenimiento de la sociedad humana y la consiguiente alteración de nuestro temperamento. Entre una y otro disponía un antagonismo de tal gravedad que impedía acogerse a la que sin duda hubiera sido la solución teórica más cómoda: la de interpretar el curso histórico como resultado de una connatural metamorfosis general de la fisonomía humana desde un tipo primitivo asocial a otro evolucionado social.

Rousseau logró sortear la dificultad, pero sin reducirla de forma absoluta. Otra cosa es que el esfuerzo empeñado para defender un punto de partida fallido - el duro asociologicismo de su antropología - diera lugar a uno de los retratos más agudos de nuestra condición social. El engarce teórico entre el estado de naturaleza y el estado de sociedad - esmerado, aunque no exento de saltos - se valió de dos recursos. Por una parte, se sirvió de la complejidad de la figuración antropológica del autor. Por otra parte, se apoyó en el detallado tratamiento del proceso de socialización como un conjunto considerablemente rico y escalonado de transformaciones en el mundo de los hombres. Nos detendremos brevemente a valorar ambos aspectos. 
En primer lugar, debe observarse que Rousseau había proyectado una naturaleza humana compleja, esto es, integrada por cualidades distintas, algunas dinámicas (como la perfectibilidad), otras mudables o frágiles (como la asociabilidad o la piedad) y algunas otras, por último, notablemente firmes (como la auto-orientación). El supuesto de esta desigual proclividad al cambio esbozaba la socialización como un proceso contra natura en algunos sentidos, pero natural en otros. De este modo pudo el autor conjugar continuidad y ruptura en su reconstrucción del devenir histórico - proporcionando coherencia y flexibilidad a su exposición-y justificar en términos antropológicos tanto el equilibrio individual del hombre en estado de naturaleza (cuando sus distintos rasgos se presumen en estado puro), como nuestra relativa tendencia al cambio y lo conflictivo del destino que nos aguarda al hilo de nuestra inversión social.

El principio dinámico de la naturaleza humana concebida por Rousseau no era otro que la perfectibilidad, cualidad vinculada al amor de si, a un impulso inherente a cuidar de uno mismo con el propósito de aségurar la supervivencia. Su consideración permitiría a la antropología rousseauniana convenir con el iluminismo, al menos parcialmente, en una idea infinitista de la naturaleza humana ${ }^{5}\left(P^{\prime} r e z, 1993-94\right)$ para la que las posibilidades de desarrollo del hombre son ilimitadas 6 , idea que implica una caracterización flexible e indeterminada de nuestra complexión. Rousseau gravitó, pues, en torno a la perfectibilidad humana en su explicación sobre la génesis y el desarrollo del proceso de socialización. A su entender, la constante pugna del hombre con el medio natural hubo de producir un perfeccionamiento sostenido de la humanidad capaz de garantizar el crecimiento continuado de mienbros en la misma. $\mathrm{Y}$ a la larga, el aumento de la densidad demográfica debió tornar inevitables los encuentros físicos fortuitos entre sujetos aislados, convivencia meramente corpörea que promovería el arranque del curso socializador del género humano. No con esto terminaba el papel de nuestra adaptabilidad constitutiva en el avance de dicho proceso: ésta aparecía también incitando directamente el roce entre sujetos al estimular prácticas de colaboración con que afianzar aún más la adaptación ecológica de la especie. En resumen, Rousseau comprendía que la facultad de perfeccionamiento del hombre acababa por deteriorar su resistencia congénita al trato social; que era la batalla del hombre consigo mismo la que decidía la aparición de la sociedad, la cual se manifestada así como una suerte históricamente necesaria, como una necesidad relativa para el hombre, tras haber sido rechazada por Rousseau como necesidad natural absoluta de nuestra complexión.

\footnotetext{
${ }^{5}$ No obstante, la propuesta rousseauniana sobre lo ilimitado de las posibilidades del hombre distaba mucho de fundar forma alguna de optimismo existencial.

${ }^{6}$ Villaverde ha apuntado la lentitud y dificultad con que tuvo lugar el cambio desde una concepción fija y acabada de la esencia humana, propia del siglo XVII, a la representación infinitista que aquí estamos exponiendo (Villaverde, 1987:125-131).
} 


\section{RIS}

REVISTA INTERNACIONAL DE SOCIOLOGIA

En segundo lugar, la trabazón teórica entre el estado de naturaleza y el estado de sociedad obtuvo del minucioso escalonamiento del proceso de socialización un apoyo notable. El análisis ontosocial de dicho curso permite descubrir una periodización de la historia natural de la especie del tipo formulado en los grandes evolucionismos organicistas del siglo XIX, pues las etapas identificadas por Rousseau en esta filosofia de la historia se disponen como formas sociales típicas. Son las siguientes:

- Primer estadio. Se inicia con el establecimiento de las primeras interacciones entre sujetos y concluye con la posterior consolidación y universalización de éstas. No hablamos aún sino de relaciones contractuales (orientadas únicamente hacia la supervivencia), y por lo tanto basadas en una reciprocidad muy superficial; restringida praxis social que produce una morfología social informe, una no-sociedad, un mero agregado. No obstante, con ella la naturaleza humana ha comenzado ya, si bien tímidamente, un profundo proceso de transformación.

- Segundo estadio. Se trata de la primera fase de la historia auténticamente social. Encuentra su punto de partida en la formación de grupos de pequeñas dimensiones, como la familia y la aldea. La convivencia en dichos grupos desata la experimentación de los primeros sentimientos de estima, inocentes afectos que degenerarán en maliciosas pasiones. La afectación de la condición humana provoca cambios sustanciales en las relaciones sociales, tanto en su contenido (que deviene narcisista), como en su forma (que se torna reflexiva). Se ordenan entonces la praxis y la solidaridad sociales propias de este periodo: por una parte claramente emocionales, pero por otra tramadas como espacios opacos plagados de incertidumbres para el sujeto. Finalmente, debe apuntarse que en esta etapa emergen la división del trabajo entre sexos y los primeros y más elementales sistemas de propiedad.

- Tercer estadio. Con el advenimiento del tercer estadio culmina la socialización de la humanidad, lo que le hace ostentar los caracteres consustanciales a lo social en estado puro. Arranca con la aparición de la división social del trabajo y la posterior constitución de la sociedad como totalidad, procesos que forjan un nuevo tipo de solidaridad social: aquella organizada por un principio externo al sujeto como es la dependencia ecológica respecto al grupo. Claro que todo ello trae también una nueva alienación del hombre (la de su capacidad reproductiva) y decide la aparición de las desigualdades sociales y la propiedad privada de los medios de subsistencia, factores que precipitan la completa depravación de nuestro temperamento y suscitan la guerra entre los individuos. Lo social se alza ya íntegramente como poder social extraño (Lamo de Espinosa, 1981) en su transcurrir por una serie de etapas que van desde la guerra entre los particulares a la guerra generalizada a gran escala, proceso a través del cual progresa la estructuración de la sociedad y la fijación de sus tendencias típicas.

De lo detallado y extenso del relato rousseauniano es posible deducir cuán cauteloso fue Rousseau al acordar las transformaciones vinculadas a la socialización: 
una seguía a otra en virtud de un lento y cuidado encadenamiento. Sin embargo, no por ello se vio libre de introducir en su crónica saltos difícilmente justificables desde el punto de vista de la coherencia interna de su obra. El más relevante se localiza en aquel momento de la historia humana en que supuestamente tenía lugar la más significativa de las transformaciones sociales de nuestra naturaleza, la misma que daría un impulso definitivo al curso socializador: la aparición del afecto hacia los semejantes. Es cierto que la hipótesis de las primeras experimentaciones afectivas entre los hombres no fue incorporada a la narración de manera abrupta, que en sí misma no era del todo contradictoria con la benevolencia natural del hombre esencial, pero aún así resultaba extraña al asociologicismo antropológico rousseauniano. El autor la concebía como una especie de mutación, como la reacción ante una circunstancia en principio externa - la convivencia- pero que finalmente mostraba la facultad de suscitar sentimientos hacia los demás, de desatar pasiones extrañas a la naturaleza de la especie, descolocando al sujeto y favoreciendo el despegue definitivo de la' socialización.

A partir de este punto Rousseau hizo descansar el avance de dicho proceso en fundamentos mecánicos (Weber, 1985:259). La experimentación afectiva, benevolente en su origen, promovía al final una nefasta dinámica, provocando nuestra perversión y moldeando el mundo de los hombres como el reino de la pecaminosidad absoluta. No sorprende, pues, que Jean Starobinsky interpretara la filosofia rousseauniana de la historia como la transposición del "mito religioso a la propia historia", y que en correspondencia distinguiera dos edades en la exposición del filósofo: "una, tiempo estable de inocencia, reino tranquilo de la pura naturaleza; otra, historia en devenir, actividad culpable, negación de la naturaleza del hombre" (Starobinsky, 1983:22).

Es indudable que Rousseau deseaba exculpar al hombre de ser responsable de su propia caída, pero no por ello evitó inculparnos, al menos parcialmente, al situar el germen último del mal en nuestra complexión. La perfectibilidad sirvió al autor como puente entre el estado de naturaleza y el estado de sociedad, entre la inocencia y la perversión. El extravío de nuestra naturaleza se realizaba en virtud del potencial ilimitado de ésta.

"[...] que esta facultad distintiva, y casi ilimitada, es la fuente de todas las desgracias del hombre; que es ella la que a fuerza de tiempo le saca de esa condición originaria, en la que pasaría sus días tranquilos e inocentes; que es ella la que, haciendo surgir con los siglos sus luces y sus errores, sus vicios y sus virtudes, lo torna a la larga tirano de sí mismo y de la naturaleza [...]”. (Rousseau, 1982:221).

De este modo, puede concederse que Rousseau ideó al hombre entrañando tanto la semilla de su supervivencia como el germen de su depravación, aportando a la creencia progresista en lo ilimitado de las posibilidades humanas su expresión negativa. 


\section{LA INVERSIÓN SOCIAL DE LA NATURALEZA HUMANA}

La investigación de la ontología social rousseauniana encuentra su materia prima en aquellos textos en que el autor planteó la escena final de la socialización de la humanidad (tercer periodo). El estudio de las alteraciones sufridas por la naturaleza del hombre proporciona un buen punto de partida. Recordemos que debido a la heterogénea disposición al cambio de nuestras distintas cualidades, la socialización resultaba un proceso normal en algunos sentidos, pero contra natura en otros. Pese a su violencia, la dialéctica de los afectos no lograba la socialización de todos y cada uno de nuestros rasgos consustanciales, lo que habría de traer el desajuste distintivo de nuestro temperamento en el estado social. El hombre está hecho para vivir en soledad, y no en sociedad, sin que la socialización pueda anular completamente la oposición de nuestra naturaleza. Es ésta la causa última de las aciagas consecuencias de la socialización sobre el carácter humano. A la luz del análisis de los textos de Rousseau las hemos condensado en tres: la pérdida del autocontrol y el equilibrio inherentes al hombre natural (alienación); la adopción de una pauta anómica; y la decadencia física y moral. Todas ellas remiten a la perturbación desencadenada en nuestra constitución por los afectos.

a) La pérdida del equilibrio y el autocontrol del individuo sobrevienen porque la experimentación amorosa termina excitando en el sujeto el ansia por la estima del ser amado. Así se induce la búsqueda de reciprocidad en el afecto y se consolida una actitud de atención sistemática hacia los otros que rompe nuestro encapsulamiento natural y desmiembra nuestro eje de sustentación, proyectándolo desde el interior del yo hacia el alter. Asimismo, el carácter de la fuerza que genera dicho desplazamiento - el deseo afectivo- potencia aún más la descompensación individual. De un lado, porque se trata de un imperativo que trastorna el conjunto de la naturaleza humana (la afecta) $\mathrm{y}$, de otro, porque su satisfacción se decide en un ámbito que es más que exterior al sujeto afectado: se ubica en el interior de los otros, en una exterioridad opaca. No obstante, el problema real radica en que esta fractura del encapsulamiento humano no comporta la destrucción total de nuestro individualismo natural: incipiente sociabilidad, por una parte; resistente autorientación, por otra. El desenlace normal de la socialización no es otro que la insociable sociabilidad, la ambivalencia egoísta-social. $\mathrm{Ni}$ siquiera la afección más desinteresada es totalmente ajena a nuestro egoísmo constitutivo. Tras la estima, se intenta retrotraer el objeto amado a los parámetros propios, rendir el mundo ante nuestro acotado yo. El hombre social es esclavo entonces de una vacilación que le priva de una vida ensimismada y feliz, de la extraordinaria integración del bon sauvage: una naturaleza perdida formulada por Rousseau en términos utópicos claramente heredados del estoicismo. 
“ $\mathrm{Oh}$, hombre! Encierra tu existencia dentro de ti, y ya no serás miserable. Quédate en el lugar que la naturaleza te asigna en la cadena de los seres, nada te podrá hacer salir de ella: no forcejees contra la dura ley de la necesidad, y no agotes, queriendo resistirte a ella, las fuerzas que el cielo no te ha dado para aumentar o prolongar tu existencia, sino sólo para conservarla como a él le place y durante el tiempo que a él le place. Tu libertad, tu poder, sólo se extienden lo que tus fuerzas naturales, no más allá; el resto es sólo esclavitud, ilusión, prestigio. La dominación misma es servil cuando atañe a la opinión: porque dependes de los prejuicios de aquellos a quienes gobiernas mediante prejuicios". (Rousseau, 1982:99).

b) En segundo lugar, puede establecerse que la anomia es el estado característico del hombre socializado. El sujeto percibe el mundo habitado por otros cuya posesión pretende - viéndose impelido a salir de sí mismo-, pero a la vez carece de la facultad física o política de esparcirse y someter el medio externo, lo que hace de ese recóndito objeto de deseo algo completamente inaccesible. La socialización arrastra a una anomia constante al suscitar en nosotros sueños quiméricos. Nos sitúa en una contradicción estructural e irremediable entre medios y fines.

c) Finalmente, la socialización provoca la inversión de la sustancia moral del sujeto, efecto inmediato de la alteración del afecto motivada por las circunstancias inherentes al tráfico emocional. Tanto la insatisfacción de las pasiones como su realización ocasionan a la larga la depravación de sentimientos que inicialmente habían sido bondadosos: desatan la envidia y el resentimiento, en el primer caso, y el envanecimiento, en el segundo.

"[...] de ahí toda sinrazón voluntaria se convirtió en ultraje, porque en el mal que resultaba de la injuria el ofendido veía el desprecio de su persona, más insoportable con frecuencia que el mal mismo. Así es como, castigando cada cual el desprecio que se le había manifestado de modo proporcionado al caso que hacía de sí mismo, las venganzas se volvieron terribles y los hombres sanguinarios y crueles [...]". (Rousseau, 1982:256).

Es ésta la historia de los afectos en el drama rousseauniano: la sincera estima, los dulces lazos, devienen celos, envidia, resentimiento, ira o vanidad, las cuales se le antojan al autor la especificidad de todo hombre social. El amor de si distintivo del estado de naturaleza se ha transformado en amor propio, determinando la muerte de la piedad, el más sencillo de los afectos y el único natural. Aquí culmina el paso del hombre desde la bondad y simplicidad naturales, a la maldad y debilidad sociales, temperamento desde el que enfrentará las relaciones con los otros, el inquietante espacio de la socialidad. 


\section{HACIA UNA TEORÍA ROUSSEAUNIANA DE LA ACCIÓN SOCIAL}

La reconstrucción teórica de la acción social descrita por Rousseau halla su punto de partida en un actor en situación ${ }^{7}$, inmerso en sociedad. De ahí que se trate al mismo tiempo de un sujeto afectado, necesitado de los otros, caído en una desapacible suerte de penuria afectiva.

¿Cuál es la vocación típica de la acción? Rousseau precisó dos posibilidades. De un lado, la acción podía perseguir un afecto recíproco, mostrando a un actor no del todo pervertido por la socialización; $y$, de otro lado, podía orientarse a la consecución de la estima pública, delatando una mudanza y perversión más radical de la voluntad del hombre. Ambas vocaciones suscitaban acciones diferentes, tanto en lo relativo a la estructura formal de ésta, como en lo referido a su contenido y valor moral: mientras que en el primer caso (el de la situación social simple) la finalidad es el otro o el afecto del otro (ordenándose una relación recíproca), en el segundo (el de la situación social compleja) el alter se presenta únicamente como requisito para el cumplimiento de la propia meta (como medio), promoviendo la reflexividad social o heterorreflexividad (Lamo de Espinosa, 1993:403,408). Lamentablemente, Rousseau reconoció en la segunda a la motivación típica de la acción social, fijando la egolatría como el impulso social genuino, como el nervio de la vida colectiva. De ahí que en correspondencia subrayara el papel que la consideración social o estima pública cumple en el proceder del sujeto. En definitiva, la acción social típica se funda en impulsos egoístas; no aspira a alcanzar una comunicación límpida con los otros, tampoco pretende la cooperación, sino que persigue enaltecer el peso del actor a través del ensalzamiento de su imagen social. Algo que forzosamente entra en competencia con la recepción pública de los otros.

“[...] cuánto ejercita y compara los talentos y las fuerzas este deseo universal de reputación, de honores y de preferencias que nos devora a todos, cuánto excita y multiplica las pasiones, y cuántos reveses, éxitos y catástrofes de toda especie causa haciendo a todos los hombres competidores, rivales o mejor enemigos, al atraer a la misma lid a tantos pretendientes. Mostraría que es a ese afán por hacer hablar a uno, a ese furor por distinguirse que nos tiene casi siempre fuera de nosotros mismos, al que debemos lo que hay de mejor y de peor entre los hombres, nuestras virtudes y nuestros vicios, nuestras ciencias y nuestros errores, nuestros conquistadores y nuestros filósofos, es decir, una multitud de cosas malas frente a un pequeño número de buenas". (Rousseau, 1982:281-282).

\footnotetext{
${ }^{7}$ La teoría social esbozada por Rousseau presenta un desarrollo dialéctico en lo que a la tensión acción-situación se refiere.
} 
Debe concederse que esta vocación difícilmente podía suscitar un obrar cristalino y explícito en la acción real, de modo que se hiciera asequible a los demás la percepción de la intencionalidad última del actor y se pudiera responder en consecuencia. Tal como fue identificada por Rousseau, la inclinación interna del sujeto socializado no se traduce en un reclamo explícito y sincero: el actor debe encubrir su verdadera intencionalidad si efectivamente desea satisfacer sus anhelos y necesidades. No hay acción sincera, sino la articulación de los medios para el logro de los fines; no hay expresión del alma, sino acción-actuación instrumental, es decir, seducción, representación y conquista. Rousseau, en su visión del actuar en el mundo, subrayaba la tendencia de los individuos a ajustarse a la consecución de la notoriedad social, tornando la vida en sociedad un proceso de aprendizaje para el éxito. El aplauso dirige la acción, tal vendría a ser la fórmula con que el autor zanjaba la superioridad del todo social sobre el sujeto e invertía el riguroso individualismo de partida.

Rousseau anotó algunas de las modalidades de la acción-tipo básica, aunque insistió especialmente en aquella en que se observa una tecnificación añadida: cuando el actor se apercibe de la universalidad de la pauta narcisista y la instrumentaliza para sus propios fines. De ahí resultan el agasajo hipócrita o la adulación vacía, afectadas artimañas desplegadas con un afán egoísta y un talante técnico. Con ello, la mera seducción pasa a ser farsa y engaño.

“[...] el ciudadano [...]. Corteja a los grandes que odia y a los ricos que desprecia; no escatima nada para obtener el honor de servirles; se jacta orgullosamente de su bajeza y de la protección de ellos y, orgulloso de su esclavitud, habla con desdén de los que no tienen el honor de compartirla [...]". (Rousseau, 1982:286).

A la fuerza, la práctica regular del proceder descrito conformaba fatalmente el ámbito de la socialidad. Asentada sobre la suma y composición de sujetos y actos egoístas, por una agitación que fuerza la falsedad, la praxis colectiva había de devenir irremediablemente esquizofrénica, pues redobla lo absurdo de los sujetos particulares. Las ocasiones ficticias que no reflejan en modo alguno el contenido de los individuos se van engarzando, tramando lo que será la dinámica social natural. Escindida entre sus fundamentos y su curso real, la acción social fragua un tejido social opaco, una situación social donde la ruptura entre el ser y el parecer es insalvable.

¿Y adónde conduce una praxis así erigida? La escena cotidiana del hombre socializado no podía ser otra que la vanidad y el desprecio, la vergüenza y la envidia. La comunicación honda y sincera entre las almas humanas es imposible. Ni siquiera la mirada es capaz de delatar al otro, de liberarlo de un juego con reglas impuestas de antemano, de un orden capaz de enajenar su ánimo.

\section{Constitución de la sociedad como totalidad}

En el relato rousseauniano, la constitución de la sociedad como sistema venía dada por la división extra-doméstica del trabajo, un fenómeno impulsado por el 
RIS

avance de la socialización y el creciente dominio del hombre sobre la naturaleza que determinaba la ampliación de la unidad funcional humana - desde los grupos primarios hasta la sociedad total-y la aparición de un nuevo principio social: la interdependencia funcional entre los sujetos. Ya instituido, el conjunto del orden social venía a descansar en dos tipos de solidaridad ${ }^{8}$. En primer lugar, un vínculo afectivo entre sujetos desencadenado por la acción de los afectos. En segundo lugar, otro puramente ecológico - derivado de la colectivización de lucha por la supervivencia - cada vez más extenso, profundo y complejo, pues las primeras especializaciones provocaban nuevas diferenciaciones, acusando el imparable movimiento de la nueva realidad social.

Sin duda, la trayectoria típica de éste nuevo orden social venía dada por la aparición y posterior acentuación de la desigualdad entre los hombres', elemento que finalmente cumplió un papel central en la teoría social rousseauniana. A juicio del autor, con la división del trabajo la satisfacción de las necesidades vitales devenía un proceso externo al individuo, lo que dificultaba en adelante la respuesta inmediata y proporcionada a éstas y terminaba trastornando su consumación. En esta incompetencia del sistema encontraba su motivo último la desigualdad, ya ostensible en el momento del intercambio.

"Las cosas, en este estado, hubieran podido permanecer iguales si los talentos hubieran sido iguales y si, por ejemplo, el empleo del hierro y el consumo de alimentos hubieran estado siempre en equilibrio exacto; pero la proporción, que nada mantenía, pronto fue rota; [...] trabajando lo mismo, el uno ganaba mucho mientras el otro apenas tenía para vivir". (Rousseau, 1982:261).

Era ésta una desigualdad promovida mecánicamente por la división del trabajo que debe añadirse a la que Rousseau concebía ocasionada deliberadamente por los hombres. La ampliación de la unidad funcional humana menoscababa las posibilidades del sujeto de controlar el proceso reproductivo, y de este modo de cuidar la equidad en el cambio, permitiendo el engaño y el fraude en un medio ya

\footnotetext{
${ }^{8}$ Nos permitimos el empleo de la terminología formulada por Durkheim en su reflexión sobre los fundamentos del orden social. Somos conscientes de que Rousseau -a diferencia de Durkheimpretendía localizar los principios del desorden social, pero también creemos que ambos buscaban igualmente los fundamentos últimos de la vida colectiva, los mismos que explican la existencia de la vida en sociedad y que los sujetos particulares vivan una vida común, sea ésta armoniosa o conflictiva.

${ }^{9}$ Es cierto que Rousseau consideraba la multiplicación de la desigualdad natural producida por la introducción de nuevas técnicas de trabajo intervenía en la ampliación de la desigualdad social, pero no concedió en absoluto el mismo peso a aquella que a los perniciosos efectos de la división del trabajo.
} 
plenamente corrupto. En cualquier caso - bien fuera ciega o conscientemente- la sociedad total basada en la división del trabajo introducía y consolidaba la desigualdad entre los hombres hasta el punto de tornarla su tendencia característica. Se planteaba entonces una especie de ley de hierro de las desigualdades sociales, una ley que barajaba tanto la acción ciega de las estructuras sociales como la voluntad típica de los actores, seres enfermos de egolatría que ansían una reiterada exaltación de su propio yo y obtienen de la supremacía política o económica métodos que facilitan la realización de sus anhelos. Voluntad humana y necesidad social concurrían en la profundización de las desigualdades sociales.

“[...] la ambición devoradora, el ansia de elevar su fortuna relativa, menos por necesidad auténtica que por ponerse por encima de los demás, inspiran a todos los hombres una negra inclinación a perjudicarse mutuamente [...]”. (Rousseau, 1982:262).

A la consideración sociológica atañe que en la acción constante de esta ley de hierro de los poderosos Rousseau viera alzarse el total de la sociedad en una forma que bien anuncia el entramado onto-social del materialismo histórico. Su reconstrucción por parte del crítico contemporáneo puede formularse en los términos siguientes. La división social del trabajo, trance natural de la historia de la humanidad, provoca la aparición de desigualdades sociales que terminan por conferir a una minoría la propiedad de los medios de que disponen los hombres para asegurar su supervivencia (infraestructura). Los poderosos, apremiados por el narcisismo y la crueldad del hombre social, comprometen su existencia custodiando y ramificando su supremacía (estructura), emprendiendo un cúmulo de acciones que se plasman en la formación de las distintas instituciones sociales. De este modo tiene lugar el pacto que constituye el Estado, toman cuerpo las magistraturas o son impulsadas las artes y las ciencias (superestructuras).

“[...] fuera el que fuese el color que pudieran dar a sus usurpaciones, de sobra sabían que sólo estaban fundadas en un derecho precario y abusivo, y que, adquiridas sólo por la fuerza, la fuerza podía quitárselas sin que pudieran tener motivo de queja [...] el rico, acuciado por la necesidad, concibió finalmente el proyecto más meditado que jamás haya entrado en mente humana: fue emplear en su favor las fuerzas mismas de quienes lo atacaban, hacer defensores suyos de sus adversarios, inspirarles otras máximas, y darles otras instituciones que le fuesen tan favorables como contrario le era el derecho natural". (Rousseau, 1982:264-265).

Se forjaba así una crítica a la política, a las artes o al conocimiento sin precedentes en la historia occidental. Una crítica radical fundada en una teoría de la sociedad desde la que se denunciaba lo ficticio del orden político, la injusticia de la ley, la falsedad de las ciencias o la vacuidad de las artes. En verdad, tan altos nombres no se le revelaban más que como la trama urdida por unos pocos para el logro de 
fines egoístas, causa y consecuencia de una nueva perversidad del hombre, pues "los vicios que vuelven necesarias las instituciones sociales son los mismos que vuelven inevitable el abuso" (Rousseau, 1982:278-280).

En resumen, la buena sociedad se revela a Rousseau como el complejo artificio de los poderosos para detentar y aumentar su predominio. Un engranaje que impondrá su dinámica incluso en el espacio relacional inmediato al sujeto: el de la acción. El juego social era ya por sí mismo una competición constante, pero ahora lo será por partida doble, pues integrará la pugna por posiciones sociales eminentes y su ostentosa exhibición. Tras la aparición de la desigualdad social, el narcisismo del hombre social deberá batallar en un espacio socialmente estructurado.

"He aquí [...] el rango y la suerte de cada hombre establecido no sólo con arreglo a la cantidad de bienes y al poder de servir o de perjudicar, sino con arreglo al espíritu, la belleza, la fuerza o la destreza, con arreglo al mérito y los talentos; y siendo estas cualidades las únicas que podían conseguir la consideración, pronto hubo que tenerlas o afectarlas, en provecho propio hubo que mostrarse diferente de lo que uno era en efecto. Ser y parecer llegaron a ser dos cosas totalmente diferentes, y de esta distinción salieron el fausto imponente, la astucia falaz y todos los vicios que son su cortejo [...] en una palabra, competencia y rivalidad por un lado, por otro oposición de intereses y siempre el oculto deseo de lograr un beneficio a costa del otro, todos estos males son el primer efecto de la propiedad y el cortejo inseparable de la desigualdad naciente". (Rousseau, 1982:262).

Nada elude la mecánica de lo social, nada evita el desorden. La sociedad se ha trabado como maldad, como pura alineación. Primero, en relación a la naturaleza humana, pues el ser social ha desfigurado al ser natural. El sujeto procede envilecido y esclavo, es incapaz de existir de acuerdo a su auténtica constitución, es más: ni siquiera sabe de ella. Segundo, en relación a la praxis social, totalmente nebulosa. El actor no sólo está impedido para conducir su socialidad, también se halla forzado a representar y engañar, y exponiéndose así a la falsedad de los otros. La oposición entre el ser y el parecer engendra una confusión generalizada en la que nadie sabe quién es quién. Finalmente, la sociedad total se despliega íntegramente como un poder social extraño: "un poder ajeno, situado al margen de los hombres, y que recorre una serie de fases y etapas de desarrollo independiente de la voluntad y de los actos de los hombres, y que incluso dirige esta voluntad y estos actos" (Marx y Engels, 1974:36). Y todo ello, para colmo, es la resultante natural de la praxis social, y no una manifestación perversa. El mal radica en la sociedad, despliega el rango de universal sociológico.

¿Acaso no hay escapatoria alguna? No puede ocultarse que Rousseau se reservó la proyección de un acto último de apropiación. Otra cosa es que éste no se basara en absoluto en la inocente naturaleza humana, sino que se proyectará 
más bien contra nuestra condición social. Perdida la inocencia natural, Rousseau ha comprendido que lo único que cabe es un ejercicio de sometimiento de la naturaleza socializada, un ejercicio lo suficientemente represivo como para extirpar el mal. Refrenar la pasión humana, aprisionar lo que a juicio de Kant despertaba las "excelentes disposiciones del hombre" (Kant, 1997:48), impedir que prenda en nosotros el engreimiento que nos hace amargos y duros: tal fue en verdad la voluntad de la más célebre utopía del siglo de las luces.

\section{ESBOZO ANALÍTICO DEL SISTEMA ROUSSEAUNIANO}

El análisis teórico de la obra de Rousseau permite establecer que el autor formuló una prototeoría general de lo social y de su evolución. Seguidamente apuntaremos algunas de las propiedades que la hacen particularmente interesante a la teoría sociológica.

En primer lugar, debe subrayarse lo que constituye aquí nuestra tesis fundamental: la articulación de una perspectiva sociológica en la obra de Rousseau. La negación de sociedades naturales o de inclinación social-natural alguna en los individuos ubicaban inicialmente a Rousseau en un nominalismo asociologicista del que, sin embargo, se distanció posteriormente. Ya nos hemos referido a las posibilidades brindadas por la hipótesis de un proceso de socialización de la humanidad, pero no está de más insistir en el hecho de que gracias a éste, el discurso del autor pudo asumir un tono sociológico ascendente e incluso desembocar en una teoría de la sociedad netamente realista que suscribe la irreductibilidad y exterioridad de la realidad social y sus dinámicas respecto a los sujetos que la conforman.

En segundo lugar, debería agradar especialmente a los teóricos de la sociología el hecho de que la filosofía social rousseauniana delinee los tres niveles de análisis que conjugarían después - a menudo con mayor dificultad - los grandes teóricos de la sociología: el del sujeto socializado, el de la praxis social y el de la sociedad como totalidad estructurada. No menos mérito presenta el hecho de que el autor mostrara su interrelación mutua al tiempo que perfilaba los rasgos diferenciales de cada uno de ellos, salvando así el dilema acción-estructura; exito en la transición desde un espacio social a otro que cabe atribuir al manejo de dos recursos teóricos contradictorios pero perfectamente articulados en la progresión rousseauniana. De un lado, Rousseau manejó cabalmente la idea de enajenación social, pues explicó gran parte de los atributos y tendencias de lo social como consecuencias no deseadas o ciegas del acontecer social del hombre. De otro lado, no renunció a comprender el mundo social como el desenlace natural de los motivos de los actores; alineación e intencionalidad, perversidad e ignorancia, se hallan conciliadas en el sistema rousseauniano. Así, la afectación de nuestro temperamento aparecía como el resultado no pretendido del proceso de socialización, un proceso cuyo origen era absolutamente ajeno a designio alguno. No obstante, afectado el sujeto, la libertad humana comenzaba a operar en el relato y, 
por ejemplo, al tiempo que la aparición de la división del trabajo y la constitución total de la sociedad se concebían como fenómenos que en modo alguno podían conocerse o preverse, el avance de su dinámica - expresado en la profundización de la desigualdad - se remitía simultáneamente a la acción ciega de las estructuras sociales y a la voluntad humana: los hombres no cedían su protagonismo ante la especialización y continuaban vertebrando el engranaje social.

En tercer lugar, se deduce de nuestro recorrido que la filosofía social rousseauniana se plantea como un sistema de teoría social asentado filogenética y ontogenéticamente. Filogenéticamente, porque hace descansar su visión de lo social en el supuesto desarrollo evolutivo del género humano, en el suceder de la especie a lo largo de su historia natural. Ontogenéticamente, porque su dibujo de los fenómenos sociales las características intrínsecas de la sociabilidad y la socialidad del sujeto. Todo ello se plasma en el desarrollo sincrónico y diacrónico de la obra de Rousseau, en una teoría general de lo social y en una lectura de la evolución histórico-natural de los fenómenos sociales.

Para concluir, no puede olvidarse el estudio de la división del trabajo social esbozado por el autor, sobre todo si se considera el contexto intelectual en que fue formulado. En este sentido, Rousseau se revela como precursor de corrientes teóricas de envergadura. Primeramente, de la concepción organicista-evolucionista para la que la lucha por la supervivencia es uno de los principios organizadores de los hechos sociales. En segundo lugar, del materialismo histórico: el autor planteó la relación entre la división del trabajo y la desigualdad y apuntó el modo cómo éstas ocasionan desequilibrios económicos y políticos capaces de comprometer la voluntad de los hombres en la reproducción del orden social. En tercer lugar $-\mathrm{y}$ por variados motivos - de la tradición durkheimiana, a la que preparó el terreno en su reconocimiento de dos fundamentos sociales diferenciables y sucesivos generados por el curso natural del género humano: uno de carácter afectivo, y otro -mucho más externo pero no menos eficaz-como es la dependencia puramente funcional entre los sujetos ${ }^{10}$.

\section{CONCLUSIONES}

Muy a menudo parece que el hombre no se ha librado de la pesadilla rousseauniana, que contradiciendo las esperanzas progresistas, la alienación y la corrupción - que no las luces - son una constante en nuestra historia reciente. La escueta revisión de ésta así permite sospecharlo, sin que la relativa generalización del bienestar, la extensión circunscrita de los derechos del hombre

\footnotetext{
${ }^{10}$ No en vano hay quien ha afirmado que "Durkheim ha sido el intermediario, por así decir, a través del que Rousseau ha dejado su huella en la moderna ciencia social”( Wolin, 1960:372).
} 
o la proliferación de la información y el conocimiento aporten argumentos irrefutables a los creyentes en el progreso civilizador. Tan grandes logros vinculados a la modernidad no han elevado en términos globales al género humano. Tal como apuntaron Tocqueville u Ortega, la modernización democrática y el ascenso económico han reducido las posibilidades de superación del hombre. El esfuerzo progresista se ha invertido en sus consecuencias y la creciente tiranía de una mayoría narcisista, hedonista y conformista (y por tanto ajena a las normas) ha desatado en muy distintos escenarios la hostilidad hacia la búsqueda de perfeccionamiento. La vulgaridad y la jactancia de ésta nos invaden por doquier en los productos de la cultura, cuando no colman con su peculiar sentido buena parte de la sociedad.

Así pues, parece que la propuesta contenida en el Contrato social rousseauniano encontró en la teoría de la sociedad-masa su más certera y dura réplica. Pero interesa subrayar que esto no resta capacidad analítica y crítica a la teoría social que fundó negativamente la teoría política rousseauniana - y que hemos tratado de sintetizar en estas páginas. Rousseau tramó con su teoría social una crítica radical a la visión liberal de la sociedad, a la teoría del orden espontáneo que establece que los vicios privados desencadenan el bienestar público. Por nuestra parte, no creemos que esta visión haya merecido el rango de universal sociológico, pues no ha dejado de evidenciar su inconsistencia empírica por más que haya conservado su belleza analítica característica. Lo prueba hoy lo que acontece en un ámbito crucial para la tradición liberal como es el de la economía. La aún cercana quiebra de algunas de las mayores empresas mundiales ha descubierto la habilidad con que la corrupción se sirve de la ingeniería financiera. Además, al violento despertar del sueño económico se ha sumado en los peores casos una crisis general de las instituciones públicas: el Estado no sólo se ha revelado inhábil para controlar las grandes empresas, también se ha delatado como una de las estructuras desde las que los poderosos satisfacen sus intereses en contra de la gran mayoría de los ciudadanos. Claro que hace tiempo ya que el régimen político occidental acusó la falta de confianza de la ciudadanía, tal como estableciera Habermas al identificar la crisis de legitimidad de las democracias. La incredulidad de los ciudadanos se consume en un sistema vertebrado por partidos políticos cada vez más adheridos a la dinámica del éxito y el poder, un sistema que sólo ocasionalmente nos sorprende socorriendo valores y normas comunes. Pero ningún otro fenómeno como la guerra muestra la corrupción y los abusos de las organizaciones, y tampoco ningún otro ofrece una imagen tan elocuente de lo ilimitado de las posibilidades del hombre. Europa lo sabe, pero no debe olvidarlo. La más reciente de las cruzadas de la humanidad ha supuesto un tormento horrible para millones de inocentes y ha brindado de nuevo la ocasión para que el hombre se desenmascare como "una bestia salvaje que no conoce el menor respeto por los seres de su propia especie" (Freud, 1974:3046). 


\section{RIS}

¿Podemos entonces fundar nuestro orden en la confianza en el ser humano? ¿Es sensato creer en las instituciones? ¿Es conveniente juzgar a las épocas y a los grupos por lo que dicen de sí? Más allá de una recuperación de las virtudes teóricas de la teoría social rousseauniana proponemos una justa recuperación de su visión del mundo de los hombres. Ha de concederse que Rousseau llevó a cabo una lectura de la sociabilidad humana mucho más rica y veraz que la ofrecida por algunas tradiciones sociológicas, sobre todo al suponer la existencia en la naturaleza humana de sedimentos de un pasado evolutivo no social, presunción que le permitiría explicar la insociable sociabilidad del hombre, lo ambivalente e incierto de la experiencia social. La representación rousseauniana de la acción y la interacción sociales no debería sufrir peor suerte. Su organización dramatúrgica no tiene competencia entre los sistemas contemporáneos que han alimentado dicha perspectiva al otro lado del Atlántico, posiblemente porque surgió en un siglo donde la vida social era vertebrada por lo comunitario al tiempo que continuamente túrbada por la modernidad. Esta confluencia propició una experimentación radical de la modernización que dio paso a una reflexión colectiva, amplia y profunda, emprendida ya no sólo desde las coordenadas intelectuales de la modernidad, sino también desde los valores de la cultura medieval y cristiana, e incluso desde la cima del mundo clásico. Esta compleja y rica herencia conformó una teoría de las pasiones y del enmascaramiento que elevó la inteligencia europea e inspiró la obra de Rousseau, bien es cierto que fraguándola como la más trágica de las teorías del orden social: lamentablemente, un modelo útil para quien desea comprender al hombre.

\section{REFERENCIAS BIBLIOGRÁFICAS}

ALTHUSSER, L. (1972), "Sobre el Contrato Social", en C. Levi-Strauss et al, Presencia de Rousseau, Buenos Aires, Ediciones Nueva Visión, pp. 57-102.

ARENDT, H. (1998), La Condición Humana, Barcelona, Paidós.

BACZKO, B. (1974), Rousseau. Solitude et communauté, París-La Haya, Mouton.

DEPRUN, J. (1979), La philosophie de l'inquiétude en France au XVIII siècle, París, Vrin.

DURKHEIM, E. (1966), Montesquieu et Rousseau, précurseurs de la sociologie, París, Librairie. Marcel Riviére. Hay traducción española a cargo de Miguel Angel Ruíz de Azúa (2000), con el título Montesquieu y Rousseau, precursores de la sociologia, Madrid, Tecnos.

(1978), Las reglas del método sociológico, Barcelona, Orbis.

(1987), La división del trabajo social, Madrid, Akal.

FREUD, S. (1974), El malestar en la cultura, Madrid, Biblioteca Nueva. 
GINER, S. (1978), "Intenciones humanas y estructuras sociales: aproximación a la lógica situacional», en J. Jiménez Blanco y C. Moya Valgañón, Teoria Sociológica Contemporánea, Madrid, Tecnos, pp. 465-500.

IGLESIAS, M.C. (1979), 'El paraiso perdido en las 'Cartas Persas' y en los 'Discursos' roussonianos», en Revista de Estudios Politicos, $\mathrm{n}^{\circ} 8$ (nueva época), pp. 165-183.

KANT, E. (1997), Filosofia de la Historia, Madrid, F.C.E.

LAMO DE ESPINOSA, E. (1981), La teoria de la cosificación, Madrid, Alianza Editorial.

(1993), "La interacción reflexiva», en E. Lamo de Espinosa y J.E. Rodríguez Ibáñez, Problemas de Teoria Social Contemporánea, Madrid, CIS, pp. 387-434.

LUKES, S. (1984), Émile Durkheim. Su vida y su obra, Madrid, Centro de Investigaciones Sociológicas.

MARX, K. y F. ENGELS (1974), La ideologia alemana, Montevideo-Barcelona, Pueblos UnidosGrijalbo.

ORTEGA y GASSET, J., (1995), El hombre y la gente, Madrid, Alianza Editorial.

PÉREZ HERRANZ, F. (1993-94), "Historia e 'historia': en torno al propuesto "fin de la historia", en Anales Universidad de Alicante de Historia Contemporánea, nº 10-11, pp. 169-190.

ROUSSEAU, J.J. (1959, 1964, 1964 y 1969), Ouvres complétes, Bibliotéque de la Pléiade, París, Gallimard.

(1982), Del Contrato Social. Discursos, Madrid, Alianza Editorial.

(1994), Escritos Polémicos, Madrid, Tecnos.

(1995), Emilio o de la educación, Madrid, Alianza Editorial.

STAROBINSKY, J. (1983), Jean-Jacques Rousseau, La transparencia y el obstáculo, Madrid, Taurus.

TODOROV, T. (1985), Frágil felicidad. Un ensayo sobre Rousseau, Barcelona, Gedisa.

VILLAVERDE, M. J. (1987), Rousseau y el pensamiento de las luces, Madrid, Tecnos.

WEBER, M. (1985), La ética protestante y el espiritu del capitalismo, Barcelona, Orbis.

WOLIN, S.S. (1960), Politics and vision: continuity and innovation in Western political thought, Boston. 